\title{
Thermal Sensor Circuit Using Thermography for Temperature-Controlled Laser Hyperthermia
}

\author{
Shinsuke Nomura, ${ }^{1}$ Masashi Arake, ${ }^{2}$ Yuji Morimoto, ${ }^{2}$ \\ Hironori Tsujimoto, ${ }^{1}$ Hiromi Miyazaki, ${ }^{3}$ Daizoh Saitoh, ${ }^{3}$ Nariyoshi Shinomiya, ${ }^{2}$ \\ Kazuo Hase, ${ }^{1}$ Junji Yamamoto, ${ }^{1}$ and Hideki Ueno ${ }^{1}$ \\ ${ }^{1}$ Department of Surgery, National Defense Medical College, Tokorozawa, Japan \\ ${ }^{2}$ Department of Integrative Physiology and Bio-Nano Medicine, National Defense Medical College, Tokorozawa, Japan \\ ${ }^{3}$ Division of Traumatology, National Defense Medical College Research Institute, Tokorozawa, Japan \\ Correspondence should be addressed to Yuji Morimoto; moyan@ndmc.ac.jp
}

Received 9 June 2017; Revised 19 August 2017; Accepted 29 August 2017; Published 9 October 2017

Academic Editor: Guanghao Sun

Copyright (C) 2017 Shinsuke Nomura et al. This is an open access article distributed under the Creative Commons Attribution License, which permits unrestricted use, distribution, and reproduction in any medium, provided the original work is properly cited.

\begin{abstract}
Laser hyperthermia is a powerful therapeutic modality that suppresses the growth of proliferative lesions. In hyperthermia, the optimal temperature range is dependent on the disease; thus, a temperature-driven laser output control system is desirable. Such a laser output control system, integrated with a thermal sensor circuit based on thermography, has been established. In this study, the feasibility of the developed system was examined by irradiating mouse skin. The system is composed of a thermograph, a thermal sensor circuit (PC and microcontroller), and an infrared laser. Based on the maximum temperature in the laser-irradiated area acquired every $100 \mathrm{~ms}$ during irradiation, the laser power was controlled such that the maximum temperature was maintained at a preset value. Temperature-controlled laser hyperthermia using the thermal sensor circuit was shown to suppress temperature fluctuations during irradiation $\left(\mathrm{SD} \sim 0.14^{\circ} \mathrm{C}\right)$ to less than $1 / 10$ of those seen without the thermal sensor circuit $\left(\mathrm{SD} \sim 1.6^{\circ} \mathrm{C}\right)$. The thermal sensor circuit was able to satisfactorily stabilize the temperature at the preset value. This system can therefore provide noncontact laser hyperthermia with the ability to maintain a constant temperature in the irradiated area.
\end{abstract}

\section{Introduction}

Laser hyperthermia (LH) is a promising and minimally invasive therapy used in various medical fields. The therapeutic indications of LH include superficial lesions such as neoplasm [1], plantar warts [2], condyloma acuminata [3], or human papillomavirus-infected skin [4]. In the field of orthopedic surgery, it has been reported that $\mathrm{LH}$ promotes bone healing for fractures and is suitable for treating osteoarthritis $[5,6]$.

When using $\mathrm{LH}$, it is important to control the heating in order to keep the temperature of a lesion within the particular thermal range that induces the maximum therapeutic effect. For this reason, various devices for temperature monitoring during LH have been developed $[7,8]$, including thermocouples [8], thermistors [9], and infrared temperature monitors [10]. Most of these temperature monitoring devices, however, only provide one value for the average temperature in a certain area. When the whole area of a target lesion is heated, the increases in temperature in small subdivided regions within the whole area are not always equal. This is because biological tissue is generally composed of small structures, each of which has different thermal characteristics. Such situations are likely to cause unintended effects during $\mathrm{LH}$, such as excessive local heating due to the spatial irregularity of the lesion. This strongly suggests that temperature monitoring devices that only show "one value" temperature information are insufficient for monitoring the heating status during LH.

One solution to this limitation is to use thermal imaging (thermography) that can obtain individual temperatures in subdivided small areas within the whole area of a target lesion. However, thermography has rarely been used as the temperature monitoring device for LH. In addition, to our 


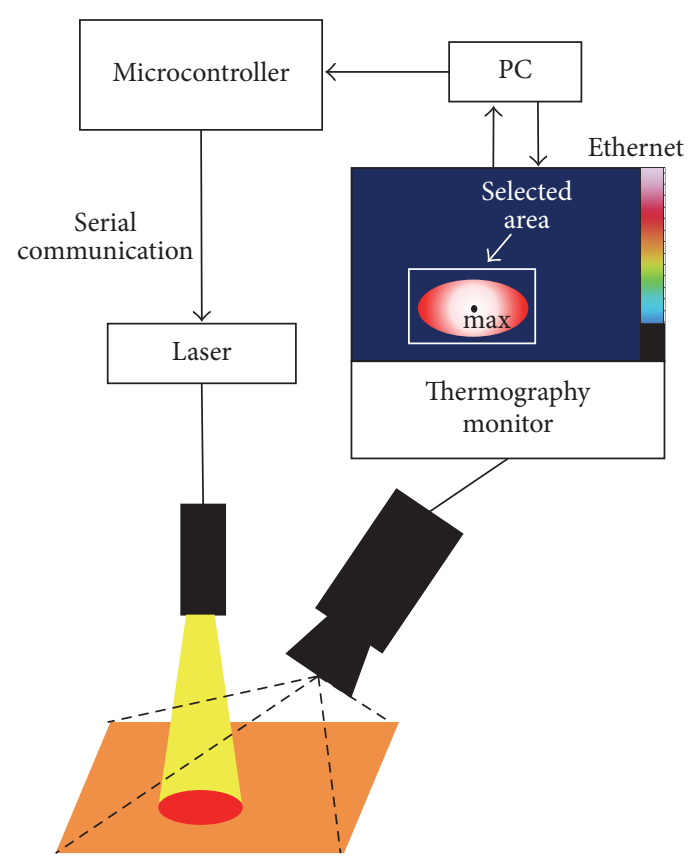

FIgURE 1: Schematic diagram of the thermal sensor circuit using thermography for laser hyperthermia. PC: personal computer.

knowledge, there are few examples where thermography has been used for temperature control in LH [11]. Therefore, an LH system using thermography has been developed, which provides feedback from each temperature in several subdivided small areas within the whole area of a target lesion to the laser output control unit (patent number: PCT/JP2016/079124).

The aim of this study is to examine the feasibility of this thermography-based thermal sensor circuit for temperaturecontrolled LH, using the skin of small animals.

\section{Materials and Methods}

2.1. Animals. Two different representative species of Mus musculus (BALB/c and C57BL/6), which are often used as laboratory animals, were selected, as the effect of the laser might differ depending on the type of mice. Female BALB/c $\mathrm{Cr}$ mice at 6 weeks of age (Japan SLC, Hamamatsu, Japan) and C57BL/ 6 mice at 6 weeks of age (Japan SLC, Hamamatsu, Japan) were fed under specific pathogen-free conditions. All animal procedures were performed in accordance with the guidelines approved by the National Defense Medical College Animal Care and Use Committee.

Hairs from the mice were removed one day before laser irradiation; hairs on the right dorsal skin were roughly cut with a clipper and were completely removed using a hair removal cream. The laser irradiation experiment with a thermal sensor circuit (described below) was carried out using one mouse of each species, and the laser irradiation experiment without the thermal sensor circuit (described below) was performed using three mice from each species.
2.2. Near-Infrared Irradiation and Thermal Dosimetry Settings. A fiber-coupled laser diode emitting an $808 \mathrm{~nm}$ laser (model FC-W-808, maximum output: $10 \mathrm{~W}$; Changchun New Industries Optoelectronics Technology Co., Ltd., Jilin, China) was used as the LH device. The fiber probe was placed above the dorsal skin of the mice such that the irradiated area was $0.20 \mathrm{~cm}^{2}$ (diameter $=0.5 \mathrm{~cm}$ ). The skin temperature was measured using a high-resolution infrared thermograph (FSV-2000, Apiste Corporation, Osaka, Japan). The maximum frame rate of the thermograph is $50 \mathrm{fps}$, the temperature accuracy is $\pm 2 \%$, and the spatial resolution is $384 \times 288$ pixels. From the whole area of pixels within an arbitrarily selected region, this thermograph automatically detects both maximum temperature and minimum temperature every $20 \mathrm{~ms}$.

2.3. Structure of the Thermal Sensor Circuit and the Temperature Control System. In order to keep the skin temperature constant, the laser power was automatically adjusted by a thermograph-based thermal sensor circuit (Figure 1). Multipoint temperatures in a selected area including the irradiated spot were captured by the thermal sensor circuit and transmitted to a PC. A microcontroller connected to the PC modulated the laser current, the magnitude of which was controlled in the following manner: the target temperature $(\operatorname{tar}(\mathrm{T}))$ that we aim to maintain in the heating area was input into the program that controls the thermal sensor circuit. In this experiment, the laser current started at $9.2 \mathrm{~A}$, which corresponded to a laser output of approximately $1.8 \mathrm{~W} / \mathrm{cm}^{2}$. The upper limits of the laser current were set to $11.2 \mathrm{~A}$ (corresponding to $7 \mathrm{~W} / \mathrm{cm}^{2}$ ). All initial setting values were provisional and could have been changed arbitrarily. The 


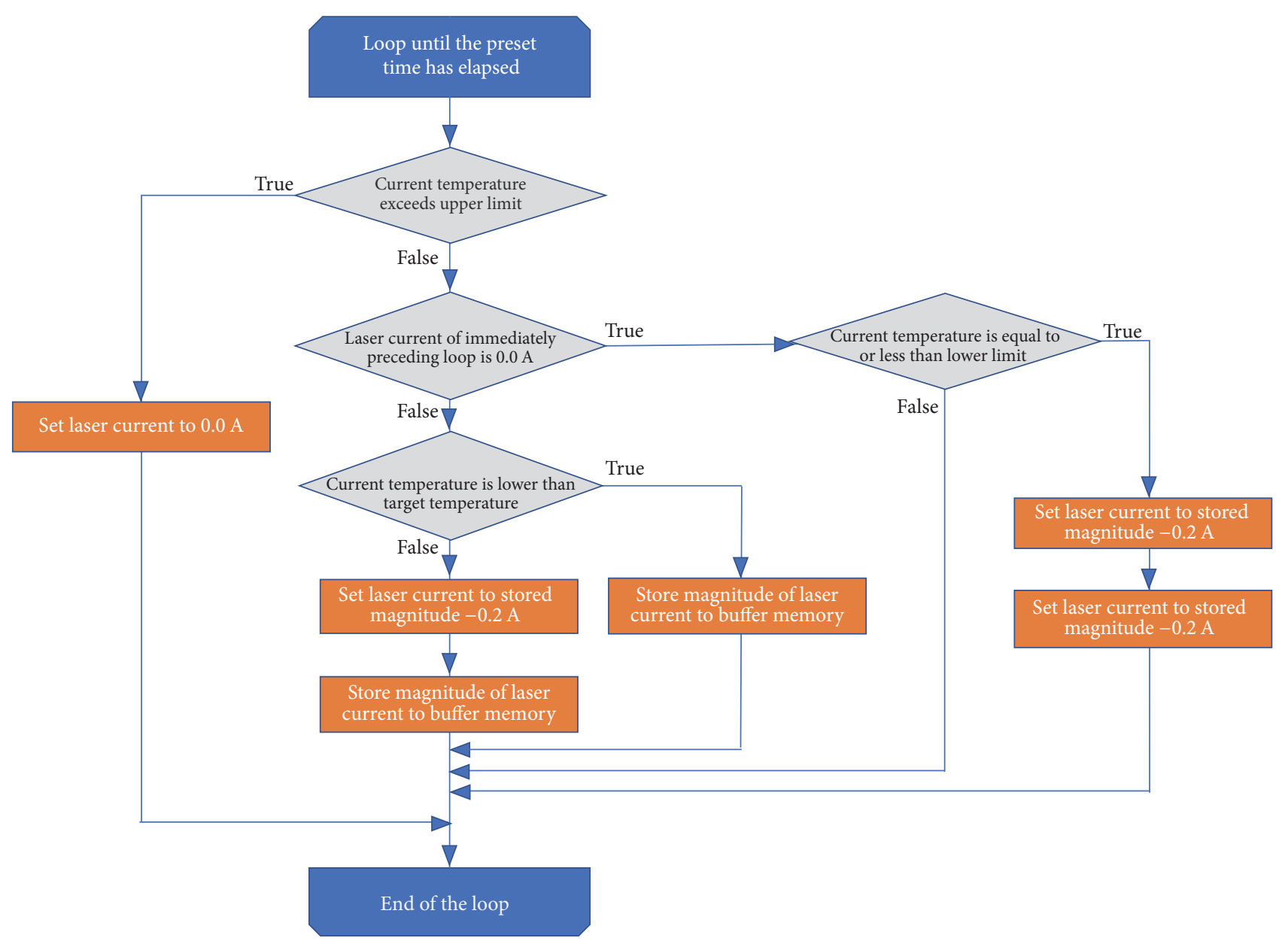

FIGURE 2: Flowchart of laser current adjustment based on temperature.

workflow of the program for the thermal sensor circuit obeyed the flowchart shown in Figure 2. The total processing time, including temperature sampling, output control, and laser irradiation, was $100 \mathrm{~ms}$. Since the rise and fall durations of the infrared laser are $1 \mu \mathrm{s}$ each, they did not affect the controlled period $(100 \mathrm{~ms})$. Typical adjustment of the laser current based on the acquired maximum temperature is described below.

For this case, the upper and lower limits were set to $\pm 0.1^{\circ} \mathrm{C}$ of $\operatorname{tar}(\mathrm{T})$. At $1 \mathrm{~s}$ after the initiation of the laser irradiation, when the acquired maximum temperature had not reached $\operatorname{tar}(\mathrm{T})$, the laser current was increased to $11.2 \mathrm{~A}$. Thereafter, when the acquired maximum temperature exceeded $\operatorname{tar}(\mathrm{T})$ by $0.1^{\circ} \mathrm{C}$ or more, the laser current was dropped to $0 \mathrm{~A}$. Then, when the acquired maximum temperature was less than $\operatorname{tar}(\mathrm{T})$ by $0.1^{\circ} \mathrm{C}$, the laser current was adjusted to $0.2 \mathrm{~A}$ below the last current value immediately before the current was turned off. When the acquired maximum temperature was still lower than $\operatorname{tar}(\mathrm{T})$, the laser current was adjusted to a value $0.2 \mathrm{~A}$ higher than the value $100 \mathrm{~ms}$ before. The variation in the current $( \pm 0.2 \mathrm{~A})$ was ascribed to the functional limitation of the laser equipment used. In the stable phase, in which the time-dependent variation in the acquired maximum temperatures was small, the laser current was gradually decreased and then repeatedly turned on and off at a certain constant value.

2.4. Laser Irradiation Protocol. Mice were placed in the left lateral decubitus position and the dorsal skin was irradiated using the laser system. The camera (FSV-210L, Apiste) of the thermograph was fixed so that the long axis of the camera was parallel to that of the laser beam. The zoom lens (FSVL212, Apiste) was adjusted so that all of the skin of the right back of the mouse was included in the monitor view. A target region for measuring the temperature was determined so as to cover the whole area of the irradiation spot (Figure 1). Regardless of the use of the thermal sensor circuit, an area of the selected target region was set at a fixed value, resulting in a $96 \times 72$ pixel area (corresponding to $29 \mathrm{~mm} \times 22 \mathrm{~mm}$ in a real area of the skin). As mentioned previously, the maximum temperature within the whole selected region was automatically detected every $20 \mathrm{~ms}$.

2.4.1. Laser Irradiation Using a Thermal Sensor Circuit. The right dorsal skin of the mouse was irradiated with the laser for $300 \mathrm{~s}$ using the thermal sensor circuit system, setting $\operatorname{tar}(\mathrm{T})$ 


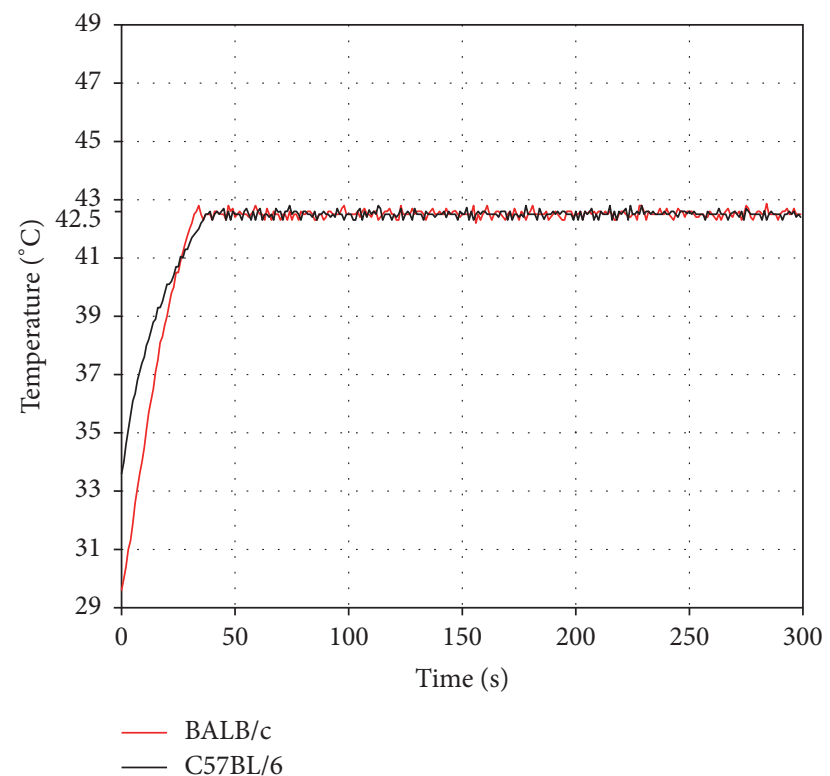

FIGURE 3: Temperature changes on the skin of the BALB/c mouse (red line) and C57BL/6 mouse (black line) under laser irradiation with the thermal sensor circuit.

at $42.5^{\circ} \mathrm{C}$. Photographs of the irradiated skin were obtained two days after the irradiation, when the pathological dermal changes (i.e., burn blisters) are usually most prominent.

2.4.2. Laser Irradiation without a Thermal Sensor Circuit. The right dorsal skin of a mouse was irradiated with the laser at a constant power density of $6 \mathrm{~W} / \mathrm{cm}^{2}$ for $300 \mathrm{~s}$, while monitoring and recording the highest temperature within the selected area using thermography. Photographs of the irradiated skin were obtained two days after the irradiation.

\section{Results}

The laser output control system integrated with the thermal sensor circuit using thermography succeeded in keeping the temperature at the target area constant during laser irradiation, even with different types of mice (Figure 3 ). Once the temperature reached the $\operatorname{tar}(\mathrm{T})\left(X, 42.5^{\circ} \mathrm{C}\right)$ after the initiation of laser irradiation (approximately $40 \mathrm{~s}$ after the irradiation), the average temperature of the $\mathrm{BALB} / \mathrm{c}$ mouse and $\mathrm{C} 57 \mathrm{BL} / 6$ mouse was $42.52^{\circ} \mathrm{C}$ and $42.51^{\circ} \mathrm{C}$, respectively, with standard deviations of $0.14^{\circ} \mathrm{C}$ and $0.14^{\circ} \mathrm{C}$ (Figure 3). The temperature value every $100 \mathrm{~ms}$ after reaching the $\operatorname{tar}(\mathrm{T})$ of $42.5^{\circ} \mathrm{C}$ was within the range of $42.5 \pm 0.1^{\circ} \mathrm{C}$ for $52.53 \%$ of the time for the BALB/c mouse and $49.71 \%$ of the time for the C57BL/6 mouse (Figure 4).

On the other hand, in the case of laser irradiation without the thermal sensor circuit, the temperature of the target area was not stabilized (Figure 5). When compared at $40 \mathrm{~s}$ after the laser irradiation, the average temperatures of the $\mathrm{BALB} / \mathrm{c}$ mice and $\mathrm{C} 57 \mathrm{BL} / 6$ mice were $44.01^{\circ} \mathrm{C}$ and $43.60^{\circ} \mathrm{C}$, respectively, with standard deviations of $1.74^{\circ} \mathrm{C}$ and $1.58^{\circ} \mathrm{C}$ (Figure 5 and Table 1). The skin temperature of one of the
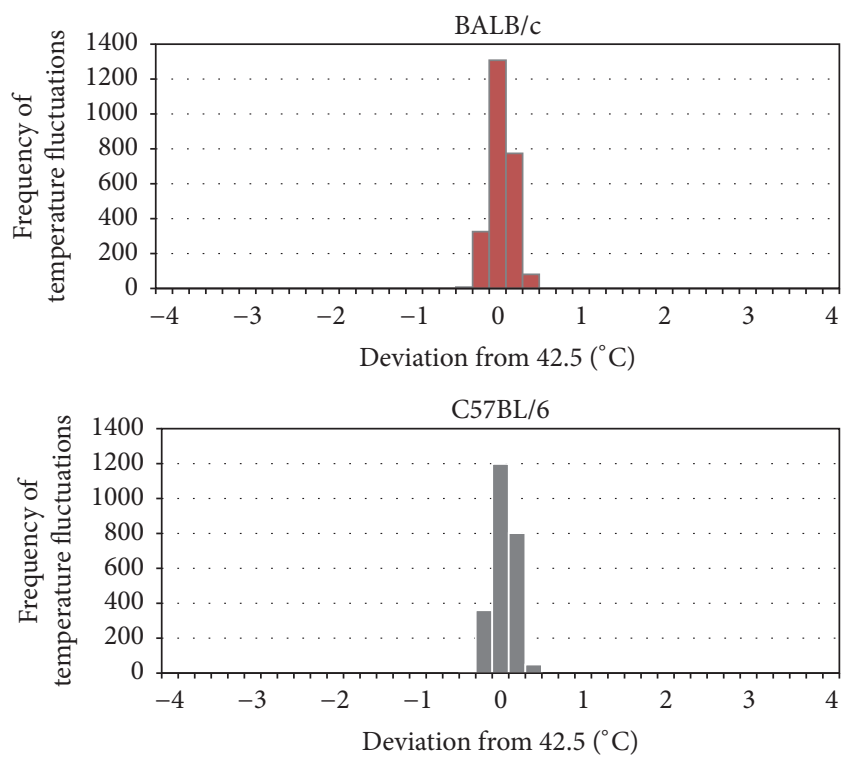

FIGURE 4: Frequency distribution of temperature fluctuations: a fluctuation was defined as the difference between $\operatorname{tar}(\mathrm{T})=42.5^{\circ} \mathrm{C}$ and the maximum temperature in the selected area, and the maximum temperature was acquired every $100 \mathrm{~ms}$.

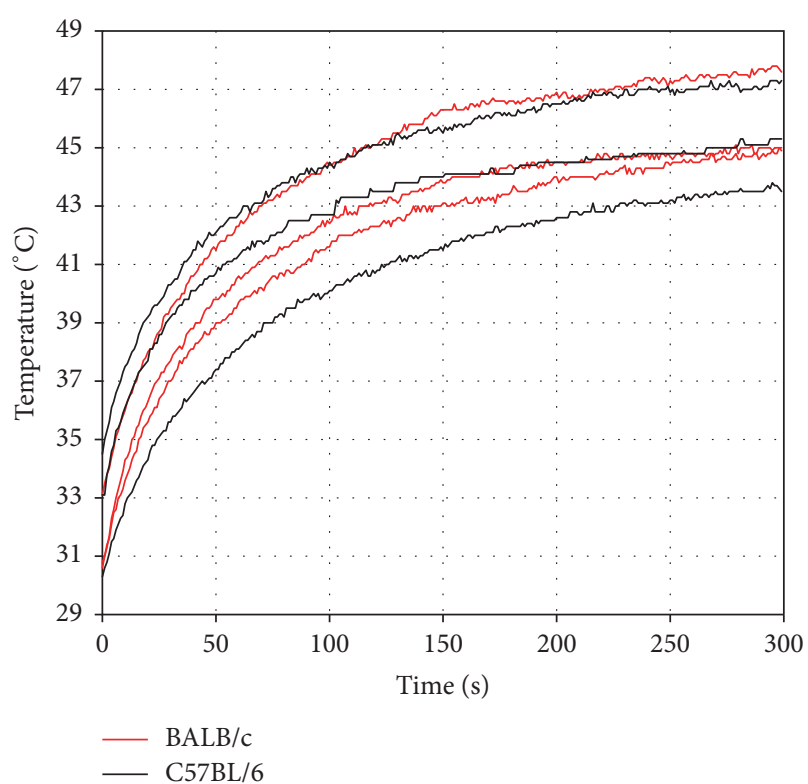

FIGURE 5: Temperature changes on the skin of BALB/c mice (red lines) and C57BL/6 mice (black lines) under laser irradiation without the thermal sensor circuit. In this case, the power density of the laser was fixed at $6 \mathrm{~W} / \mathrm{cm}^{2}$.

$\mathrm{BALB} / \mathrm{c}$ mice (number 3) exceeded $47^{\circ} \mathrm{C}$, and the animal showed blister formation corresponding to the irradiated area, suggesting the occurrence of a first-degree burn (Figure 6(a)). Histopathological examination (Hematoxylin and Eosin stain) of the BALB/c mouse (number 3) revealed that the squamous epithelium was not seen in the irradiated area, which is consistent with a first-degree burn (Figure 7). All of 


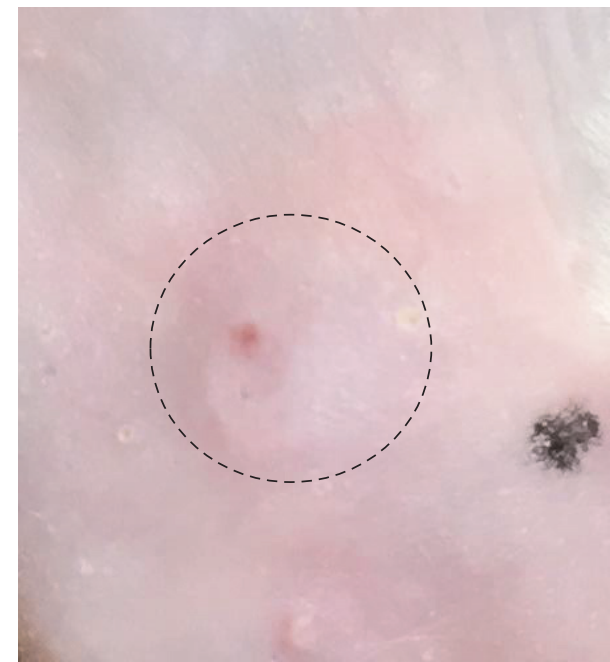

(a)

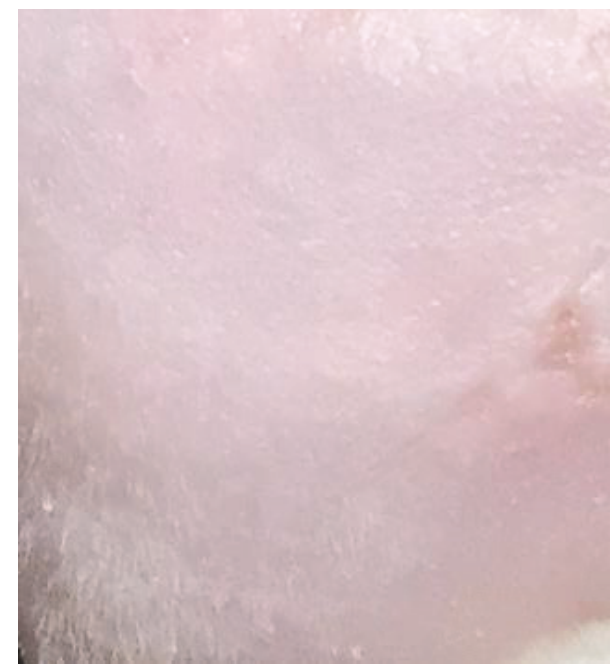

(b)

FIgURE 6: Photographs of the skin two days after irradiation with a fixed power density $\left(6 \mathrm{~W} / \mathrm{cm}^{2}\right)$. (a) BALB/c mouse number 3; bubbles were seen in the skin (dotted circle line). (b) BALB/c mouse number 2; no change was seen in the skin.

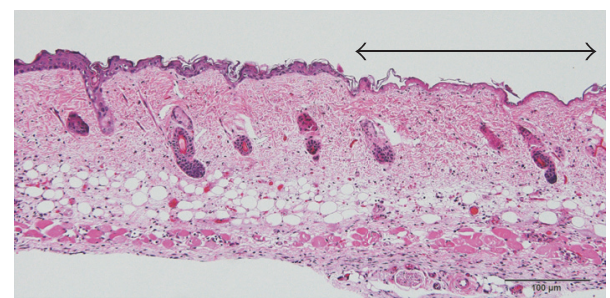

Figure 7: Microscopic image of the skin corresponding to Figure 6(a) (BALB/c mouse number 3), marked using Hematoxylin and Eosin stain. Loss of the squamous epithelium is seen (both ends of arrow) in the area of the laser-irradiated spot.

TABLE 1: The average value and standard deviation of the temperature sampling data every $100 \mathrm{~ms}$ from 40 seconds after the start of laser irradiation until the end of irradiation.

\begin{tabular}{lcccccc}
\hline & Number & Max & Mean & SD & Mean & SD \\
\hline & $(1)$ & 45.10 & 42.83 & 1.77 & & \\
BALB/c & $(2)$ & 47.83 & 43.46 & 1.60 & 44.01 & 1.74 \\
& $(3)$ & 45.02 & 45.73 & 1.86 & & \\
\hline \multirow{3}{*}{ C57BL/6 } & $(1)$ & 45.31 & 41.50 & 1.87 & & \\
& $(2)$ & 47.34 & 43.75 & 1.31 & 43.60 & 1.58 \\
& $(3)$ & 43.83 & 45.56 & 1.55 & & \\
\hline
\end{tabular}

the other mice showed no obvious change in the irradiated skin (Figure 6(b)).

\section{Discussion}

The present study showed that temperature-controlled laser hyperthermia using the thermal sensor circuit exhibited excellence in maintaining a $\operatorname{tar}(\mathrm{T})$. Temperature-controlled laser hyperthermia using the thermal sensor circuit resulted in suppression of the temperature fluctuations during irradiation ( $\mathrm{SD} \sim 0.14^{\circ} \mathrm{C}$ ) to less than $1 / 10$ of those seen without the thermal sensor circuit $\left(\mathrm{SD} \sim 1.6^{\circ} \mathrm{C}\right)$.

The degree of temperature increase due to the $\mathrm{LH}$ depends on several factors, such as the laser wavelength, power density of the laser, density of melanin pigment, distribution of capillaries in the epidermis, and concentration of hemoglobin in the blood $[12,13]$. Therefore, it is important to monitor the temperature of the lesion during $\mathrm{LH}$.

For effective LH, it is necessary to heat the lesion up to the $\operatorname{tar}(\mathrm{T})$; however, overheating the lesion should be avoided. Although the maximum temperature was around $45^{\circ} \mathrm{C}$ in most of the mice irradiated without the thermal sensor circuit, some of the mice bore low-temperature burn, as shown in Figure 6. Therefore, the $\operatorname{tar}(\mathrm{T})$ should be kept within an appropriate range. An optimal temperature range for $\mathrm{LH}$ is considered to be from $42^{\circ} \mathrm{C}$ to $45^{\circ} \mathrm{C}$; this range promotes the migration and maturation of Langerhans cells [14], which activate immune responses.

Temperature-controlled systems using the combination of a hyperthermic apparatus and a noninvasive temperature monitor have been developed, and some of them have been used clinically [3, 7, 8, 10, 14-16]. A noncontact type thermal monitoring system, other than thermography, has also been reported $[3,10,14]$; however, it only shows one value for the average temperature in a certain area. In contrast, the present thermal sensor circuit is unique in its ability to acquire multipoint temperatures (thermal images) using thermograph.

There are several challenges to be addressed to advance the present system toward practical use in clinical applications. The first challenge is to verify the effectiveness of the thermal sensor circuit when applied to lesions such as tumors and plantar warts. Most of the neovessels in such lesions often show a poor vasodilating property; thus, the delivered 


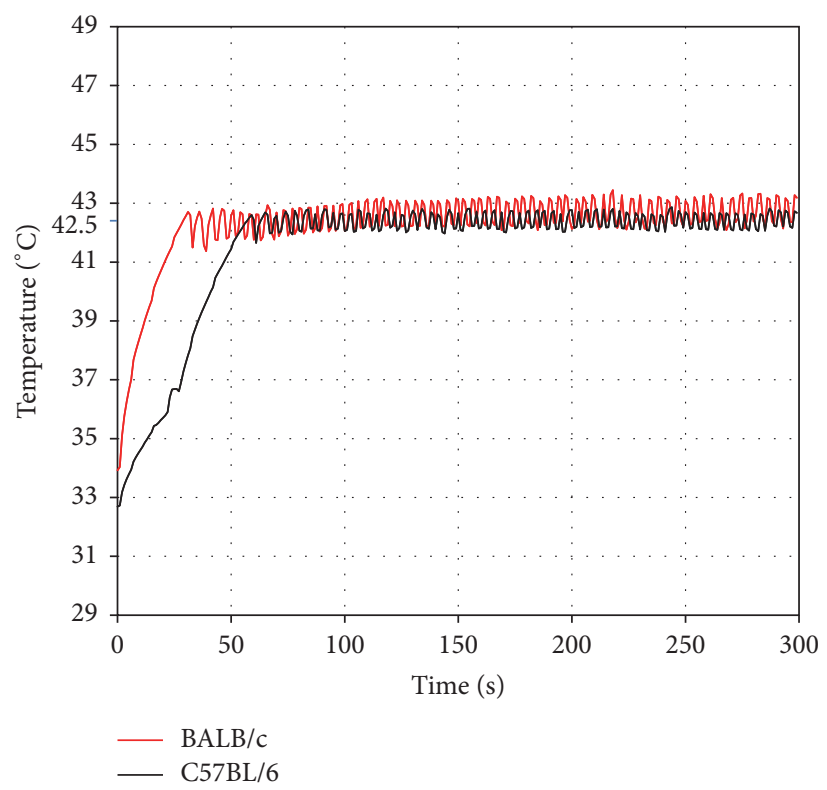

Figure 8

heat tends to be retained owing to insufficient blood flow, and the temperature of the lesions is liable to increase [17]. The second challenge is to improve the temperature control. The program that controlled the thermal sensor circuit in the present study was a simple modification of the on-off control method. Approximately $50 \%$ of the temperature values every $100 \mathrm{~ms}$ after reaching the $\operatorname{tar}(\mathrm{T})$ of $42.5^{\circ} \mathrm{C}$ were within the range of $42.5 \pm 0.1^{\circ} \mathrm{C}$. The use of other control methods may further suppress the temperature fluctuation. One candidate is the proportional-integral-derivative (PID) control method, which is reported to correct the fluctuation of temperature more tightly than the on-off control method [7, 18]. The third challenge is to establish a method for the estimation of the temperature inside an irradiated target from the surface temperature, since thermography in principle measures the surface-to-air temperature.

\section{Conclusions}

Our developed thermal sensor circuit using thermography for temperature-controlled LH successfully suppressed the temperature fluctuation during laser irradiation to less than $1 / 10$ of that seen when compared to irradiation without the thermal sensor circuit.

\section{Appendix}

The thermal sensor circuit for temperature-controlled laser hyperthermia worked well in the case using thermography. However, thermography is only applicable for sensing the surface temperature of a heated object. Hence, to demonstrate the usefulness of the thermal sensor circuit even when sensing the interior temperature of a heated object, an additional experiment was performed using a thermocouple.
A needle-shaped thermocouple probe (HYP0, OMEGA Engineering Inc., Stamford, CT) combined with a data logger (TC08, Pico Technology, Cambridgeshire, UK) was used for measuring an intradermal temperature. The probe consists of an extremely small type $\mathrm{T}$ (copper-constantan) thermocouple implanted in a stainless steel needle $(\varphi=0.2 \mathrm{~mm}$; length $=$ $25 \mathrm{~mm})$. The temperature accuracy is $\pm 0.2 \%$. Using the thermal sensor circuit, the intradermal temperature was automatically captured through the thermocouple every $100 \mathrm{~ms}$.

The needle-shaped thermocouple probe was inserted into a mouse intradermally and was advanced so that the needle top (metal joint portion) was placed in the center of the laser irradiation field. One BALB/c mouse and one C57BL/6 mouse were used.

Even using the thermocouple probe, the thermal sensor circuit worked well and fulfilled the temperature-controlled laser hyperthermia. Once the temperature reached the target temperature $(\operatorname{tar}(\mathrm{T}))\left(X, 42.5^{\circ} \mathrm{C}\right)$ after the initiation of laser irradiation, the average temperatures of the $\mathrm{BALB} / \mathrm{c}$ and $\mathrm{C} 57 \mathrm{BL} / 6$ mice were $42.66^{\circ} \mathrm{C}$ and $42.41^{\circ} \mathrm{C}$, respectively, with standard deviations of $0.45^{\circ} \mathrm{C}$ and $0.29^{\circ} \mathrm{C}$ (Figure 8). The temperature value captured every $100 \mathrm{~ms}$ after reaching the $\operatorname{tar}(\mathrm{T})$ of $42.5^{\circ} \mathrm{C}$ was within the range of $42.5 \pm 0.1^{\circ} \mathrm{C}$ for $14.13 \%$ of the time for the BALB/c mouse and $15.17 \%$ of the time for the C57BL/6 mouse.

The thermal sensor circuit worked well with an invasive temperature measuring device such as a thermocouple. However, in this case, the initial temperature rise was slower and the temperature fluctuation during the thermalequilibrium phase was larger compared to those when using the thermograph. These findings suggest that, in the case of laser hyperthermia, the temperature control in deep lesions is accompanied by a large fluctuation in the temperature of the lesions when using an on-off type sensor circuit. 


\section{Conflicts of Interest}

The authors report no proprietary or commercial conflicts of interest in any product mentioned or concept discussed in this article.

\section{Authors' Contributions}

Shinsuke Nomura and Masashi Arake have contributed equally to this work.

\section{Acknowledgments}

The authors would like to acknowledge Editage (https:// www.editage.jp) for English language editing. This work was supported by the Japan Society for the Promotion of Science (Kakenhi) under Grant no. 17H02114.

\section{References}

[1] Y.-C. Yang, Y.-W. Cheng, C.-S. Lai, and W. Chen, "Prevalence of childhood acne, ephelides, warts, atopic dermatitis, psoriasis, alopecia areata and keloid in Kaohsiung County, Taiwan: A community-based clinical survey," Journal of the European Academy of Dermatology and Venereology, vol. 21, no. 5, pp. 643649, 2007.

[2] Y. Ma, W. Huo, Y.-X. Hong, H.-D. Chen, and X.-H. Gao, "Successful clearance of facial common warts by local hyperthermia: Report of two cases," Dermatologic Therapy, vol. 25, no. 4, pp. 386-388, 2012.

[3] X. Wang, X.-H. Gao, X. Li et al., "Local hyperthermia induces apoptosis of keratinocytes in both normal skin and condyloma acuminata via different pathways," Apoptosis, vol. 14, no. 5, pp. 721-728, 2009.

[4] X. Gao and H. Chen, "Hyperthermia on skin immune system and its application in the treatment of human papillomavirusinfected skin diseases," Frontiers of Medicine in China, vol. 8, no. 1, pp. 1-5, 2014.

[5] J. Son, Y.-B. Kim, Z. Ge, S.-H. Choi, and G. Kim, "Bone healing effects of diode laser $(808 \mathrm{~nm})$ on a rat tibial fracture model," in vivo, vol. 26, no. 4, pp. 703-709, 2012.

[6] J. Y. Lee, S. U. Lee, T. Lim, and S. H. Choi, "Healing effects and superoxide dismutase activity of diode/Ga-As lasers in a rabbit model of osteoarthritis," In Vivo, vol. 28, no. 6, pp. 1101-1106, 2014.

[7] X. Feng, F. Gao, C. Xu, L. Gaoming, and Y. Zheng, "Self temperature regulation of photothermal therapy by laser-shared photoacoustic feedback," Optics Letters, vol. 40, no. 19, pp. 44924495, 2015.

[8] T. H. Nguyen, S. Park, K. K. Hlaing, and H. W. Kang, "Temperature feedback-controlled photothermal treatment with diffusing applicator: theoretical and experimental evaluations," Biomedical Optics Express, vol. 7, no. 5, pp. 1932-1947, 2016.

[9] K. Ivarsson, L. Myllymäki, K. Jansner, U. Stenram, and K.-G. Tranberg, "Resistance to tumour challenge after tumour laser thermotherapy is associated with a cellular immune response," British Journal of Cancer, vol. 93, no. 4, pp. 435-440, 2005.

[10] W. Huo, X.-H. Gao, X.-P. Sun et al., "Local hyperthermia at $440 \circ \mathrm{c}$ for the treatment of plantar warts: a randomized, patientblinded, placebo-controlled trial," Journal of Infectious Diseases, vol. 201, no. 8, pp. 1169-1172, 2010.
[11] S. A. Shevchik, G. V. Zhukov, I. N. Golovanov, K. G. Linkov, V. V. Barun, and V. B. Loschenov, "Temperature control technique for laser hyperthermia," in Proceedings of the Advanced Biomedical and Clinical Diagnostic Systems VI, usa, January 2008.

[12] J. Ortonne, "Photoprotective properties of skin melanin," British Journal of Dermatology, vol. 146, no. s61, pp. 7-10, 2002.

[13] B. S. Kwak, B. S. Kim, S.-H. Song, H. O. Kim, H. H. Cho, and H.-I. Jung, "Direct measurement of the in vitro hemoglobin content of erythrocytes using the photo-thermal effect of the heme group," Analyst, vol. 135, no. 9, pp. 2365-2371, 2010.

[14] X. Li, X.-H. Gao, L. Jin et al., "Local hyperthermia could induce migrational maturation of Langerhans cells in condyloma acuminatum," Journal of Dermatological Science, vol. 54, no. 2, pp. 121-123, 2009.

[15] K. Arunachalam, P. F. Maccarini, and P. R. Stauffer, "A thermal monitoring sheet with low influence from adjacent waterbolus for tissue surface thermometry during clinical hyperthermia," IEEE Transactions on Biomedical Engineering, vol. 55, no. 10, article no. 12, pp. 2397-2406, 2008.

[16] X.-h. Gao, D. Gao, X.-P. Sun et al., "Non-ablative controlled local hyperthermia for common warts," Chinese Medical Journal, vol. 122, no. 17, pp. 2061-2063, 2009 (English).

[17] A. Chicheł, J. Skowronek, M. Kubaszewska, and M. Kanikowski, "Hyperthermia - Description of a method and a review of clinical applications," Reports of Practical Oncology and Radiotherapy, vol. 12, no. 5, pp. 267-275, 2007.

[18] L. Sun, C. M. Collins, J. L. Schiano, M. B. Smith, and N. B. Smith, "Adaptive real-time closed-loop temperature control for ultrasound hyperthermia using magnetic resonance thermometry," Concepts in Magnetic Resonance Part B: Magnetic Resonance Engineering, vol. 27, no. 1, pp. 51-63, 2005. 


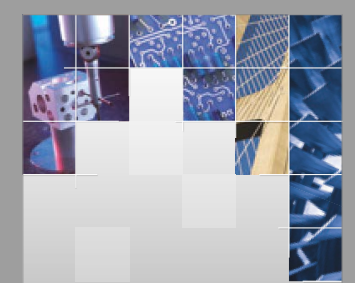

\section{Enfincering}
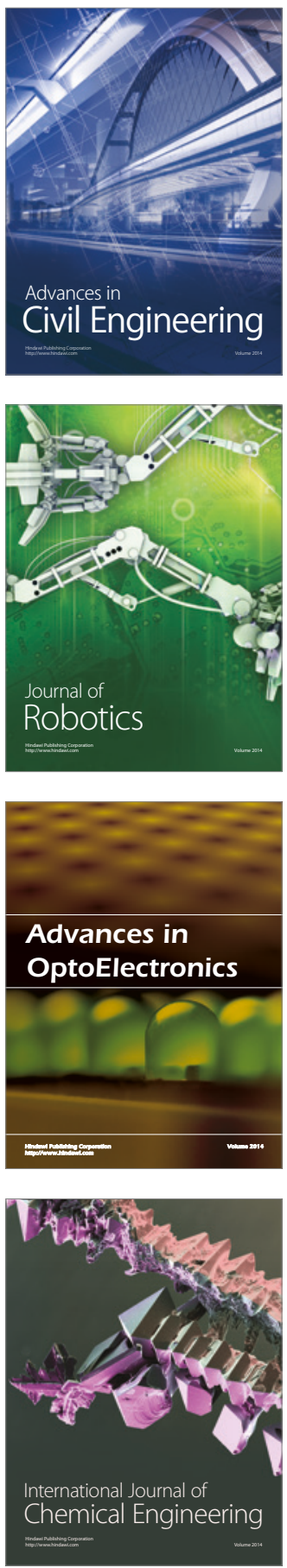

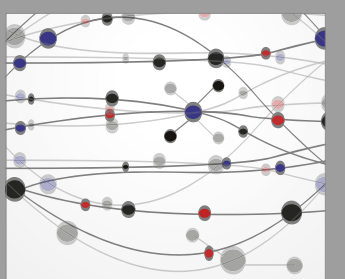

The Scientific World Journal

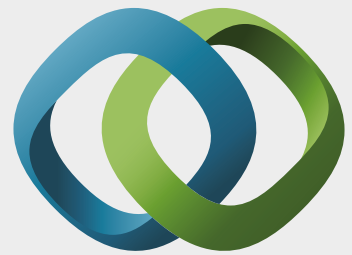

\section{Hindawi}

Submit your manuscripts at

https://www.hindawi.com
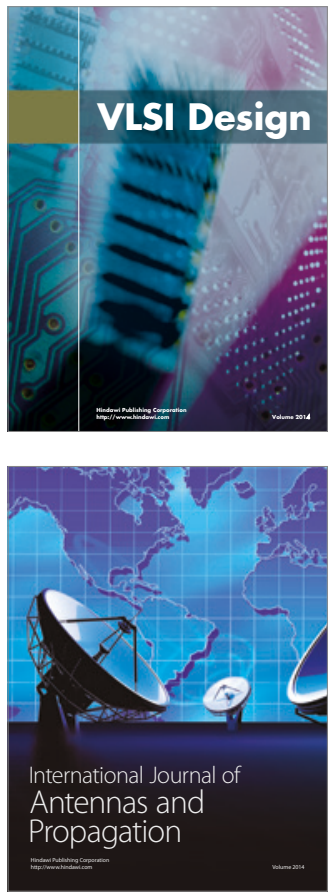

\section{Rotating}

Machinery
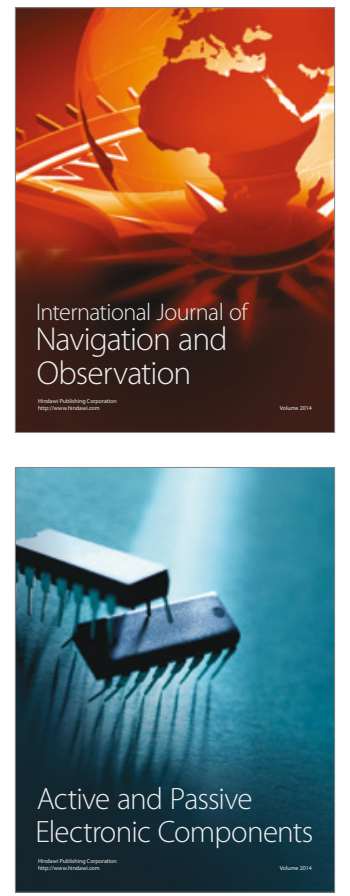
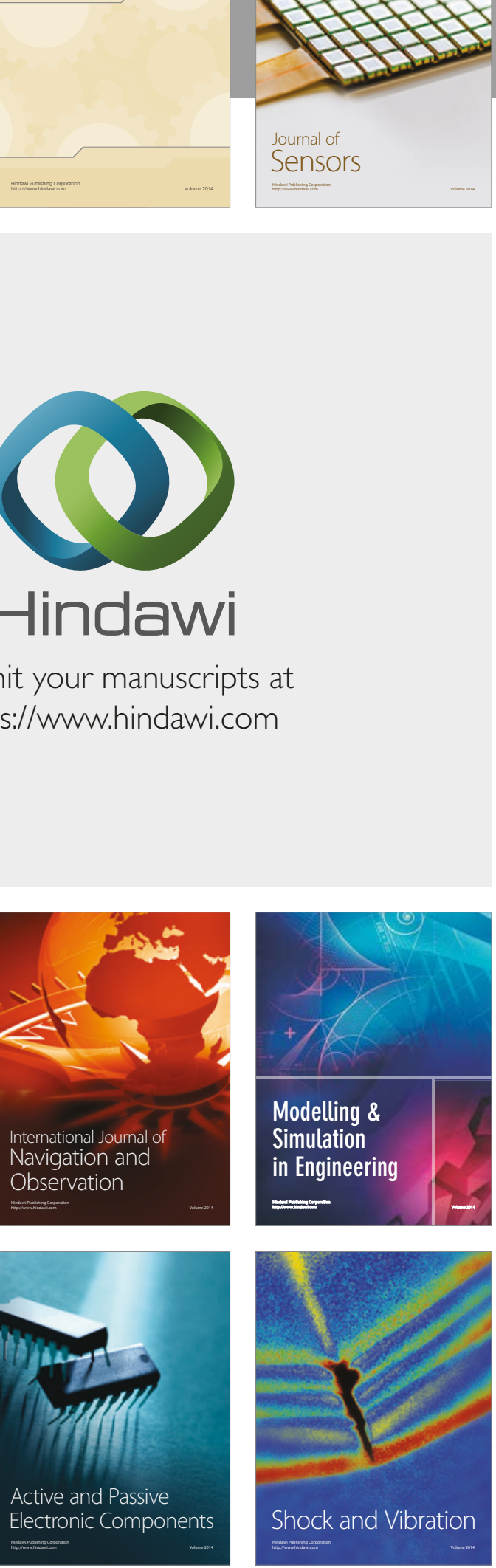
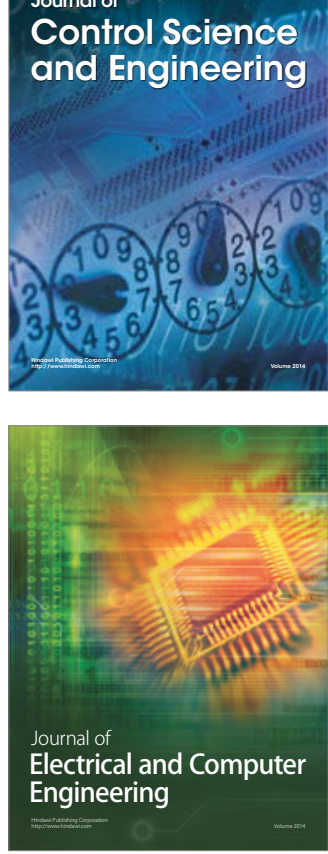

Distributed

Journal of

Control Science

and Engineering
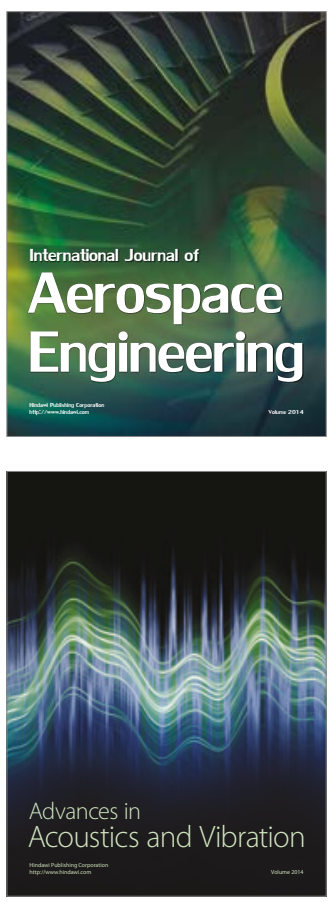

Sensor Networks 